Cita bibliográfica: Covarrubias Ramírez, R. y Rodríguez Bautista, J.J. (2018). Multifuncionalidad territorial y turismo. Implicaciones socioculturales, económicas y ambientales en destinos rurales emergentes. Un caso de estudio en Comala, Colima. Investigaciones Turísticas (15), pp. 79-107. http://dx.doi.org/10.14198/INTURI2018.15.04

\title{
Multifuncionalidad territorial y turismo. Implicaciones socioculturales, económicas y ambientales en destinos rurales emergentes. Un caso de estudio en Comala, Colima
}

\author{
Territorial multifunctionality and tourism. Sociocultural, economic and environmental \\ implications in emerging rural destinations. A case study in Comala, Colima
}

Rafael Covarrubias Ramírez. Universidad de Colima y Universidad de Guadalajara, México. covra@ucol.mx

Juan Jorge Rodríguez Bautista. Universidad de Guadalajara, México. jiorge65@gmail.com

\section{RESUMEN}

El concepto de multifuncionalidad rural fue usado por primera vez hacia finales del siglo XX, como resultado de las transformaciones que se venían dando en las áreas rurales, generando nuevas funciones económicas, socioculturales y ambientales, más allá de las atribuciones tradicionales del territorio. Diversos autores resaltan al turismo como una de esas funciones recientes. En este trabajo se articula la multifuncionalidad con el turismo, y se analizan las implicaciones territoriales que se pueden dar en las comunidades donde se está introduciendo el turismo. Para los fines de este artículo, se toma el caso del municipio de Comala, en el estado mexicano de Colima, identificado nacional e internacionalmente como el lugar donde se desarrolla la mítica historia de "Pedro Páramo", obra literaria del escritor Juan Rulfo y como uno de los Pueblos Mágicos de México. La metodología de investigación se basó en el análisis documental de publicaciones científicas sobre tópicos de multifuncionalidad y de su relación con el turismo así como informes estadísticos y técnicos. El trabajo empírico se realizó con el apoyo de la observación participante con diversos recorridos en el área de estudio. Los hallazgos más relevantes evidencian importantes transformaciones socioeconómicas y ambientales, tales como el cambio del uso del suelo, modificaciones en las actividades productivas tradicionales, al igual que cambios en el sistema de tenencia de la tierra -de ejidal a propiedad privada-. También se identifican casos de mejoramiento económico y empoderamiento de mujeres de origen indígena, mediante la creación y consolidación de negocios turísticos.

Palabras clave: multifuncionalidad, territorio rural, turismo, implicaciones territoriales. 


\section{ABSTRACT}

The concept of rural multifunctionality was first used towards the end of the twentieth century, as a result of the ongoing transformations in the rural areas, which had been generating new economic, socio-cultural and environmental functions, going beyond the traditional functions of the territory. A number of authors highlight tourism as one of these recent functions. This paper articulates multifunctionality with tourism and the territorial implications that can occur in the communities where tourism is being introduced are analyzed. This article discusses the case of the municipality of Comala, in the Mexican state of Colima, identified nationally and internationally as the place where the story of "Pedro Páramo", literary work of the writer Juan Rulfo, takes place and as one of the Magical Towns of Mexico. The research methodology is based on the documentary analysis of scientific publications that address the relationship of multifunctionality with tourism as well as technical and statistical reports. The empirical work has been carried out through participant observation with several walks in the study area. The most relevant findings show important socio-economic and environmental transformations, such as the change in land use, changes in traditional productive activities and changes in the system of land tenure -from ejidal to private property-. It also identifies cases of economic improvement and empowerment of women of indigenous origin, through the creation and consolidation of tourism businesses.

Keywords: multifunctionality, rural territory, tourism, territorial implications

\section{INTRODUCCIÓN}

El carácter multifuncional del territorio rural es el resultado de los procesos de mutación vinculados principalmente con la agricultura (conjunto de actividades y conocimientos de las personas en torno al campo), ante la necesidad de que los campesinos y otros productores primarios diversifiquen sus formas de generación de ingresos (Ilbery, 1998), como consecuencia de las presiones de los cambios económicos, socioculturales y tecnológicos globales, pero también, según explica Hernández (2009), como resultado de las nuevas relaciones urbano-rurales, que transforman los universos sociales y culturales, pasando de una dicotomía a una ambivalencia (Moreno, 2017). Ante estos cambios en el uso del territorio, se viene apostando por el carácter multifuncional de la agricultura como enfoque capaz de integrar su actividades productivas con las funciones no-productivas (Wilson, 2009a) tales como las ambientales, sociales, patrimoniales o paisajísticas de su práctica (Brouwer y van der Heide, 2009; Fagioli et al., 2017; Nogar, 2007; Ricart, 2016; Silva, 2010).

El turismo en el contexto rural emerge como una de las nuevas funciones de esos territorios, convirtiéndose en un medio de diversificación del espacio rural y en una opción de desarrollo local, sobre todo para territorios rurales en crisis o bajo presión, creando vínculos cercanos entre la producción agrícola y el territorio, combinando esto con otras actividades, en particular con el turismo (Aznar et al., 2006). Diversos estudios abordan los vínculos de la multifuncionalidad territorial con el turismo, sobre todo en los territorios rurales, desde posturas que evalúan los resultados de la relación multifuncionalidad-turismo tanto positivos como negativos. 
Entre las aportaciones de los estudios realizados en México destaca el de Pérez-Ramírez et al. (2011), quienes analizan la configuración de la actividad turística desde la perspectiva de la nueva ruralidad, y subrayan que dicha actividad está generando profundas transformaciones socioculturales y físicas para las comunidades campesinas. Desde el enfoque de la dominación capitalista, Cruz-Coria et al. (2012) analizan la configuración del paisaje turístico en el espacio rural, de manera específica en la región norte del Caribe Mexicano. Los autores señalan que tanto el Estado como la iniciativa privada reconocen la multifuncionalidad del territorio rural, a partir de que éste ha perdido su significación económica tras la terciarización de las actividades productivas, que ha dado entrada a la transformación de tal espacio, convirtiéndolo en un tejido denso y tupido de infraestructuras y equipamientos para el turismo. Este trabajo generaliza que el turismo en la región estudiada es realizado por capital trasnacional. En otro trabajo, Santana-Aispuro (2014) analiza los factores que afectan al territorio y su funcionalidad, a través de las transformaciones de la micro-cuenca de Tapalpa, uno de los destinos turísticos de montaña de mayor afluencia en el estado de Jalisco.

En la región europea, se han identificado las aportaciones de Sáez y Barrado (2008), Dissart y Marcouiller (2012), Niño-Gutiérrez et al. (2015), analizan la multifuncionalidad en diferentes regiones de España, valorando las potencialidades de transformar las producciones tradicionales y la identidad paisajística en servicios y bienes turísticos y de ocio. De igual forma revisan cómo esta nueva actividad puede mejorar los niveles de competitividad territorial de estos ámbitos rurales. Paracchini et al. (2016) plantean un modelo para medir indicadores de la multifuncionalidad de la agricultura en el contexto europeo, a través de tres componentes: el paisaje protegido, el turismo como un producto consumido in situ y productos agrícolas consumidos ex situ, específicamente aquellos identificados como denominación de origen protegida (PDO, por sus siglas en inglés).

Reconociendo que el turismo se produce y se consume en el territorio, esta actividad ha tenido que apropiarse de espacios reales tales como zonas costeras, montañas o comunidades originarias, dotados de recursos naturales y culturales, que han tenido que adecuarse para dar paso a las instalaciones, equipamiento e infraestructura necesarios para su funcionamiento y para dar la mejor satisfacción y comodidad a los visitantes (Granados, 2008). Uno de los espacios geográficos que está teniendo mayor auge para el desarrollo del turismo es el territorio denominado rural, como consecuencia de la demanda de actividades turística en entornos naturales y auténticos, además de que a partir de ello, algunos se podrían considerar como destinos turísticos rurales emergentes. El tema cobra relevancia al reflexionar que los territorios rurales contienen la mayoría de los sistemas de recursos naturales que proveen alimentos, esparcimiento y servicios ecosistémicos para alguna región dada, pero su manejo ha ido cambiando debido a diversos motivos como la crisis económica del propio sector rural, el crecimiento de la población que se traduce en la expansión o creación de asentamientos humanos, el crecimiento de la frontera agrícola y ganadera, e incluso la localización industrial hacia estas zonas, hace que esa transformación afecta al espacio natural que se requiere para el equilibrio ecológico. Las preguntas que surgen a partir de dichas reflexiones son: ¿qué elementos definen la multifuncionalidad del territorio rural?, ¿qué relación existe entre multifuncionalidad y turismo? y finalmente ¿qué implicaciones resultan de dicha relación? 
El municipio de Comala, en el estado mexicano de Colima, seleccionado como caso de estudio, está apostando a un desarrollo económico basado en la diversidad de nuevas funciones del territorio rural, que paulatinamente han ido sustituyendo las actividades vinculadas con las prácticas agrícolas que históricamente habían sido el principal motor de subsistencia de sus habitantes. Una de esas nuevas funciones es el turismo, que se basa en el uso de los elementos naturales y culturales del territorio, que se consideran atractivos para los visitantes nacionales y extranjeros.

Los resultados permiten una aproximación al entendimiento del proceso de expansión del turismo asociado con las nuevas funciones del medio rural, que se refleja en importantes modificaciones en la ocupación del territorio y sus recursos, propicia cambios en el uso del suelo, transformación de las actividades productivas tradicionales, así como la transición de régimen de la propiedad, que está pasando de la modalidad ejidal a privada. Se identifica que todavía se mantiene un control local y que la mayoría de los emprendimientos turísticos son propiedad de habitantes locales, así mismo se destacan claros procesos de empoderamiento de grupos de mujeres y de jóvenes de origen indígena.

\section{OBJETIVOS Y METODOLOGÍA}

El diseño metodológico se basó en un enfoque cualitativo, fundamentado en el paradigma interpretativo (Jennings, 2010; Veal, 2006). El trabajo está organizado en dos objetivos. El primero se enfoca en analizar el debate y los principales abordajes teóricos en torno a la multifuncionalidad territorial, para responder a las preguntas ¿qué elementos definen la multifuncionalidad del territorio rural? y ¿qué relación existe entre multifuncionalidad y turismo?. Esta fase se desarrolló examinando un conjunto de trabajos académicos, principalmente de Europa y América, publicados entre finales del siglo pasado y principios del actual. Las publicaciones científicas se obtuvieron de bases de datos electrónicas tales como Elsevier Scopus, Science Direct, Redalyc y Dialnet así como de libros o capítulos de libros especializados en el tema, utilizando como palabras clave multifuncionalidad, nueva ruralidad, post-productivismo, y su combinación con turismo, así como implicaciones territoriales.

El segundo objetivo responde a la pregunta ¿qué implicaciones resultan de la relación MFR-turismo?. Para ello, esta etapa se orientó a la evaluación de tales implicaciones, distinguiéndolas en ambientales, socioculturales, económicas y político-administrativas, desde la postura de que el turismo constituye una de las nuevas funciones del espacio rural. La caracterización del área de estudio se realizó mediante un diagnóstico situacional, alimentado principalmente de fuentes secundarias tales programas de ordenamiento, informes estadísticos y técnicos de organismos públicos, para la obtención de indicadores demográficos y económicos, aspectos geográficos y ambientales así como de la dinámica turística en el municipio. El diagnóstico del desarrollo turístico se basó en el modelo de ciclo de evolución del área turística de Butler.

Para contrastar la teoría se seleccionó como caso de estudio la zona rural del municipio de Comala, en el estado de Colima (México), localidad que fue puesta en los ojos del mundo por la obra literaria "Pedro Páramo", de Juan Rulfo (1955), y en septiembre de 
2002 fue incorporado al Programa de Pueblos Mágicos de México ${ }^{1}$. Desde entonces ha experimentado un crecimiento en el desarrollo del turismo, tanto en la zona urbana como en la rural y actualmente es un destino protagonista en la región occidental de México. En 2012 obtuvo el reconocimiento de la Secretaria de Turismo (SECTUR), como uno de los mejores Pueblos Mágicos de México. Tal crecimiento se caracteriza por una creación espontánea y desordenada de negocios, lo que se está traduciendo en un conjunto de efectos territoriales de tipo político-administrativo, socio-cultural, económico-productivo y físico-ambiental, que ponen en riesgo la sostenibilidad del territorio y de las actividades que ahí se desarrollan.

En el trabajo empírico, la recolección de información se basó en la observación participante. Esta técnica consiste en obtener información "de lo que se ve, se oye o se siente, bajo circunstancias específicas e incluso, impredecibles" (Allsop et al., 2010, p. 209), tras involucrarse en una interacción regular y prolongada con gente y en lugares que el investigador busca estudiar, adentrándose en el ambiente local del participante (Ribeiro y Foemmel, 2012). Es un método en el que el observador toma parte en las actividades cotidianas, rituales, interacciones, y eventos de la gente que es estudiada como uno de los medios de aprender sobre los aspectos explícitos y tácitos de su cultura (Ibid.).

Las implicaciones del turismo en territorios rurales que se muestra en tabla No. 3, constituyeron las categorías de análisis, con las que se elaboró una matriz para el registro de notas de campo, que permitió documentar la observación realizada en los alrededores, las conversaciones y algunas rutinas de hábitos y costumbres de los grupos locales en tres comunidades rurales en las que se concentra la actividad turística: Suchitlán, La Nogalera y Cofradía de Suchitlán. Durante los recorridos, los investigadores fueron guiados ocasionalmente por un habitante de estas las localidades, para facilitar la identificación y acceso a los sitios objeto de estudio, y en muchos casos, para proporcionar información complementaria. Los sucesos y conductas observadas, tanto positivos como negativos, se catalogaron en tres grupos: implicaciones económico-productivas, implicaciones socio-culturales e implicaciones físico-ambientales.

\section{DE LAS FUNCIONES TRADICIONALES A LAS NUEVAS FUNCIONES DEL TERRITORIO RURAL}

\subsection{Funciones tradicionales del territorio rural}

El territorio rural es un fenómeno espacial que se extiende a través de regiones, paisajes, áreas naturales, tierras agrícolas, pueblos y otros centros urbanos más grandes. Está compuesto por un tejido económico y social diverso y complejo, que también es el hogar de

1. El Programa de Pueblos Mágicos de México (PPMM) es un programa de política turística coordinado por la Secretaria de Turismo (SECTUR) del Gobierno Federal de México, iniciado en 2001, que actúa directamente sobre las localidades como una marca distintiva del turismo en México. Incluye localidades mexicanas con atributos simbólicos, historias, leyendas, hechos trascendentes, cotidianidad, magia, enmarcados en sus manifestaciones socio-culturales (https://www.gob.mx/sectur/articulos/pueblos-magicos-herencia-que-impulsan-turismo, última consulta26-oct-2017) 
una gran riqueza de recursos y tradiciones (Tapiador, 2008), con dimensiones históricas, políticas, sociales, culturales y ecológicas, que tienen una realidad propia (Echeverri y Ribero, 2002). Su importancia radica en que este territorio acogió a la mayor parte de la población humana hasta el siglo XX y en la actualidad continúa generando el grueso de alimentos, energía y materiales requeridos por toda la sociedad.

Hasta finales de la década de 1940, el mundo rural se limitaba a cumplir con una serie de funciones apegadas a las prácticas productivas tradicionales, sin exceder en mucho a la agricultura. Esas funciones tradicionales, según Brouwer y van der Heide (2009), pueden ser definidas como la capacidad del territorio para proveer bienes y servicios que satisfacen las necesidades, demandas y expectativas de los humanos, directa o indirectamente. Desde esa perspectiva, el medio rural se define y se organiza por su alto contenido de elementos naturales (Zuluaga, 2000) y por las actividades relacionadas con labores agrícolas que sus habitantes, activamente ocupados, realizan en el campo (Méndez, 2005), como cultivos y ganadería de diversas especies, además del comercio de los productos obtenidos por éstos, las actividades forestales, la pesca, la extracción de recursos naturales, entre otras (Pérez, 2001).

A la par de dichas funciones, se identifican peculiaridades, también tradicionales del medio rural, tales como una baja densidad poblacional (Echeverri y Ribero, 2002; Tapiador, 2008), una infraestructura reducida, poca población económicamente activa en los sectores secundarios y terciarios, además de un claro dominio de un sistema agro-silvícola (CésarDachary y Arnaiz-Burne, 2006). Lo anterior confirma que el medio rural aún conserva un acervo considerable de prácticas ancestrales, cuya importancia ecológica, cultural, social y económica, son reconocidas por diversos individuos y organismos de peso internacional (Sepúlveda, 2008); pero, esos espacios agrarios que han sido construidos en buena parte por las actividades agrícolas, ganaderas y silvícolas, como argumenta Gómez-Mendoza (2001, p. 114), "ya no pueden mantenerse a través de ellas, o mejor dicho, ya sólo pueden mantenerse parcialmente a través de ellas". Entonces, surgen políticas y programas que claman por una diversificación de las actividades en el medio rural, que permitan alternativas de ingresos económicos.

Con el paso del tiempo, los territorios rurales han sido testigos de profundas transformaciones relacionadas con sus funciones y sus estructuras, pasando por la innovación tecnológica y técnicas de producción, marcos políticos, ideologías (Wilson, 2009a), la expansión de la frontera urbana y agrícola que traen consigo la presión sobre los ecosistemas y sus recursos. Ese fenómeno se ve incrementado a finales de la Segunda Guerra Mundial y hasta finales de los años 80 del siglo XX, cuando se apuesta por una industrialización de la agricultura, sustentada, como señala Armesto (2005), en una concepción tecno-económica. A esta fase se le conoce como productivista (Armesto, 2005; Evans, 2001; Jay, 2004) y se caracteriza por una agricultura depredadora de la biodiversidad, definida por la explotación y la subsidiaridad.

La intensidad de dichos cambios ha sido mayor en los países de Europa que los de América Latina, debido al mayor desarrollo económico general de los primeros (Banco Mundial y FAO, 2003), pero también a la creciente pérdida de importancia de la agricultura como motor 
del dinamismo de los espacios rurales y por una desagrarización (Evans, 2001; Marín, 2015; Pérez, 2001; P. Rubio, 1999) del medio rural y la consecuente migración y envejecimiento de su población (Trpin, 2005), aunado al crecimiento urbano y a la globalización, en los segundos, bajo un esquema de presión dinámica y constante en el desarrollo de las economías locales (Rodríguez, Uribe y Reyes, 2011).

Dichas transformaciones han motivado diversas posturas, llegando incluso a la tesis del fin de lo rural, sugerida por Jean (1987), que plantea la inexistencia o abandono del medio rural al convertirse los campesinos en urbanos, o su reducción a una mera representación construida (Ratier, 2002). Otras posturas más conservadores advierten que con el acercamiento de lo urbano con lo rural se plantea solamente el fin de la dicotomía rural-urbano y se da paso a lo que se ha denominado como el "continuum" rural-urbano (Moreno, 2017). Paralelamente emergen términos que tratan de explicar lo que resulta de esa fusión, tales como el periurbano, rururbano (Dirven, Perico, Sabalain, Baeza, y Faiguenbaum, 2011), e incluso el ruralopolitano (ONU-HABITAT, 2009).

En las nuevas funciones se incluye no sólo la producción agrícola de alimentos, sino también la protección de la biodiversdiad y de los paisajes rurales, la generación de empleo (Armesto, 2005) y la conservación de los valores ambientales (Hernández, 2009). Sin embargo, en muchos casos, esas nuevas funciones vienen acompañadas de transformaciones más aceleradas que se pueden identificar junto con el auge industrial, tanto en Europa como en América Latina, ya que esta última región ha tomado como modelo a los países desarrollados (Kay, 2001), intentando copiar esquemas de modernización que, incluso, no han sido totalmente satisfactorios en su lugar de origen. A partir de esos hechos, el territorio rural ha estado siendo invadido, como plantea Zuluaga (2000), por elementos construidos que usan el territorio rural para llevar servicios o conectar ciudades, tales como carreteras, vías de tren, redes de transmisión eléctrica, canales y presas para almacenamiento de agua y producción de energía eléctrica, facilidades turísticas, entre otros, sumados a la industrialización de la agricultura, que interrumpen y trasforman los flujos naturales, fragmentan los ecosistemas y propician nuevos patrones de empleo y poblamiento, lo que concluye con grandes cambios de uso de suelo y provoca también una transición hacia una nueva funcionalidad de entorno rural, fenómeno que ha sido denominado en el medio latinoamericano como "nueva ruralidad" o en otras latitudes como "multifuncionalidad" y "post-productivismo".

\subsection{Transición a las nuevas funciones del territorio: multifuncionalidad rural}

En el debate por identificar y conceptualizar las transformaciones del mundo rural, caracterizadas principalmente por la incorporación de funciones diferentes a la agricultura tradicional, desde principios de los 90 se han venido planteando diversos conceptos y teorías que tratan de explicar los factores, procesos e impactos resultantes de dichas mutaciones. Si bien estos enfoques no se asumen como sinónimos, sí se puede decir que convergen para describir un mismo fenómeno, que se considera multidimensional debido a que incluye cambios económicos, culturales, sociales, demográficos y políticos (Ilbery, 1998). Entre éstas se subrayan la teoría de la multifuncionalidad rural/agrícola (Brouwer y van der Heide, 2009; FAO, 1999; Hernández, 2009; Knickel y Renting, 2000); la de la transición del productivismo al 
post-productivismo (Ilbery y Bowler, 1998; Rubio Terrado, 1999; Wilson, 2001, 2009), y la de la nueva ruralidad (Ávila-Sánchez, 2015; de Grammont, 2004; Echeverri y Ribero, 2002; Moreno, 2017). Las dos primeras surgen y tienen mayor influencia en el contexto europeo o en economías desarrolladas, mientras que la última, es un planteamiento más enfocado a la realidad latinoamericana².

Se identifica entonces que la naturaleza, cambios y futuras trayectorias de los sistemas agrícolas y rurales son discutidos y conceptualizados a través del debate teórico (Wilson, 2009b), desde diferentes posturas que integran intereses de disciplinas como la geografía, la economía, la sociología, la antropología, la filosofía, la ecología y ciencias ambientales, convirtiéndose así en un asunto multidisciplinario, aunque también debatible e incluso ambiguo (Hernández, 2009).

El término multifuncionalidad rural (MFR) surge en 1992, en la Cumbre de Río (Ledesma, 2014; Ricart, 2016; Segrelles, 2007), acuñado por la FAO, en medio de la crisis del mundo rural, con el propósito de explicar los cambios y nuevos procesos que se estaban dando, pero también para proponer estrategias que permitieran sacar adelante estas zonas, haciendo necesaria la evolución de las políticas agrícolas que se debieron ajustar ante el cambio de dirección del medio rural (Bassi y De Poi, 2010; Hernández, 2009), intentando desarrollar una agricultura competitiva. Por ello se entiende que en esa región, la MFR está más ligada a las decisiones políticas vinculadas con los subsidios destinados al desarrollo agrícola (AcevedoOsorio, 2016), y para cumplir con tales propósitos, las (nuevas) funciones de la agricultura y de los recursos naturales se clasificaron en tres categorías: función económica, función ambiental y función social (Echeverri y Ribero, 2002), tomando en cuenta que los territorios proveen servicios adicionales - más allá del rol de producción primaria- que se ubican más en la categoría de bienes públicos (Bergstrom, 2005).

De forma simple, Wilson (2009a, p. 382) define la MFR como "la agricultura que tiene muchas funciones" y como "la antítesis de la monofuncionalidad, en la que la agricultura se limita a funciones de producción de alimentos y fibras". En palabras de Hernández (2009, p. 337), "no significa otra cosa que incorporar dentro de las funciones tradicionales (producción de materias primas y alimentos) todas esas otras funciones en la agricultura por las que los agricultores no reciben bienes que pueden ser intercambiados en el mercado".

La MFR, como modelo, plantea la necesidad de dejar atrás la vieja imagen de un campo atrasado y pobre, que no solamente debe cumplir la función básica de producir alimentos, sino que puede y debe asumir de manera simultánea la función ambiental (Ledesma, 2014), lo que aporta el signo de diversificación a las tareas agrícolas y favorece la generación de una amplia variedad de productos, tangibles e intangibles, en función del modo en que use el suelo y según los sistemas de producción que se usen (Martínez, 2002).

La importancia de la MFR (recursos, factores, procesos, actores e instituciones) es reconocida por diversos autores, como un criterio básico para comprender los nuevos procesos

2. Con el propósito de complementar las explicaciones de las transformaciones que suceden en los territorios rurales, diversos autores incluyen algunas variaciones a los conceptos ya mencionados, tales como pluriactividad (Kay, 2009), plurifuncionalidad (Hernández, 2009), postruralidad (P. Rubio, 1999). 
socioculturales, económicos, políticos y ambientales que suceden actualmente en el ambiente rural (Borrelli, 2016; Brouwer y van der Heide, 2009; Knickel y Renting, 2000; Ledesma, 2014; Nogar, 2007; Ricart, 2016; Rovai y Andreoli, 2016; Silva, 2010; Zuluaga, 2000), y se valora como una respuesta al colapso del paradigma agrícola productivista, que ha generado un daño socio-ambiental no deseado, crisis de salud, escasez de alimentos y exclusión rural (Rivas y Quintero, 2014), dando prioridad al desarrollo local o endógeno, concibiendo al medio rural como un sistema pluriactivo susceptible de múltiples usos (Plaza-Gutiérrez, 2006). Estas aportaciones revaloran el papel del territorio rural y de su producción tradicional basada en la agricultura, como un factor necesario para la generación de empleo-riqueza, y como un importante soporte material para la conservación de los espacios naturales, pero consideran también que la producción tradicional por sí sola es insuficiente para mantener un tejido social vivo y dinámico en muchas zonas rurales, por lo que es necesario incorporar otras funciones no agrícolas, como el turismo mismo.

En el contexto europeo, como parte del debate sobre las nuevas funciones del espacio rural, la literatura académica aborda la transición del productivismo al post-productivismo, para explicar los cambios en la agricultura contemporánea (Wilson, 2009a), y la asocia de manera directa con la MFR. Este concepto fue acuñado a principios de los 90 (Evans, 2001) y se formuló con el propósito de contar con un modelo menos intensivo y más acorde con otros criterios de calidad territorial y de compromiso con la biodiversidad (Plaza-Gutiérrez, 2006), para favorecer actividades más diversas y las inclusiones de valores sociales, culturales, ambientales propios del medio rural (Kramkowski y Mulvihill, 2017). Según Armesto (2005) la palabra post-productivismo se toma prestada del inglés y se empieza a aplicar en el territorio británico. Por su parte, Evans (2001) explica que el concepto se usa para transmitir la idea de un cambio importante en las prioridades agrícolas y precisa que desde entonces se ha usado como una muletilla de moda para resumir un complejo cambio agrario o incluso rural. De manera categórica Armesto (2005) afirma que el post-productivismo simboliza la aplicación de la MFR.

De manera casi simultánea, en el espacio latinoamericano se introduce el concepto de la nueva ruralidad como un enfoque de los estudios rurales (Kay, 2009). Aunque esta noción ha sido interpretada de muchas maneras, autores de esa región como Ávila (2005, 2015), Echeverri y Ribero (2002), Gómez (2001), Llambí (2012), Ruiz et al. (2008), coinciden, en primer término, que los territorios rurales se han venido transformando y que el concepto de nueva ruralidad describe genéricamente las maneras de organización y el cambio en las funciones de los espacios tradicionalmente no urbanos. Posturas en contra de la globalización como Monterroso y Zizumbo (2009), Rubio (2006), Vilchis-Onofre et al. (2016), enfatizan que la nueva ruralidad es una estrategia de reproducción de capital impuesto por organismos internacionales, en el marco de la globalización neoliberal, que limita las actividades agrícolas y condena la soberanía alimentaria de una nación, ya que la población rural debe hacerle frente a la pobreza con actividades que van más allá de la tradición agrícola. Por su parte, Gómez-Pellón (2015) explica la nueva ruralidad como las formas alternativas a la ruralidad tradicional, que obligan a los campesinos a encontrar empleo en actividades distintas a la agropecuaria. Tales acciones han propiciado también la fragmentación del territorio y la expulsión de los campesinos, quienes emigran, dentro o fuera del país, en busca 
de alternativas de subsistencia. En otras palabras, la nueva ruralidad se puede entender como una "propuesta sociológica que interpreta las transformaciones del territorio rural a partir de la implementación de las políticas neoliberales, la economía ecológica, la economía campesina, el neo-institucionalismo como promotores de la aceptación de la existencia de racionalidades alternas" (Rosas-Baños, 2009, p. 97).

Algunos autores sugieran que la MFR es una característica de la nueva ruralidad (Nogar, 2007) y viceversa, o que el productivismo lo es de la MFR. Más allá de los significados, en los tres paradigmas se observa que los vínculos campo-ciudad se estrechan cada vez más y que tienen su origen en las transformaciones del mundo rural, junto con la necesidad de adaptarse y evolucionar de acuerdo con las nuevas necesidades de la población, tanto rural como urbana. Desde esas nociones, se deben advertir también los efectos de la globalización en el territorio rural, como lo explica Rosas Baños (2013), en términos de desestructuración de las relaciones sociales en la comunidades, profundización de la pobreza, explotación, degradación ambiental, proletarización y la productividad se ve como estrategia de supervivencia y resistencia.

Aunque en los trabajos analizados se aprecia que la denominación de MFR y post-productivismo está más vinculada con las políticas agrarias y con las publicaciones académicas europeas y que en Latinoamérica se ha posicionado más la llamada nueva ruralidad, ninguno de los tres paradigmas se puede limitar a una zona en particular ni se pueden generalizar a nivel mundial, incluso, se expresan de formas muy diferentes en cada región del mundo, dependiendo de características geográficas, culturales, de los niveles de desarrollo y madurez de la regiones (FAO, 1999); los campesinos desempeñando múltiples actividades en medio de las transformaciones del mundo rural es una realidad que se viene dando en la mayoría de los países, aunque en condiciones económicas y sociales desiguales.

\subsection{Implicaciones territoriales del turismo en espacios rurales}

Las nuevas funciones emergentes del territorio rural incluyen el turismo (en sus modalidades de turismo rural, agroturismo, ecoturismo, entre otras), así como las actividades recreativas y la vivienda, sin abandonar las prácticas propias de ese espacio (Armesto, 2005; Brouwer y van der Heide, 2009; Hernández, 2009; Ivars, 2000). De manera que el turismo en territorios rurales no se da por generación espontánea, sino que es resultado de la suma de demanda de experiencias y productos relacionados con la naturaleza y lo rural, de las nuevas funciones incorporadas a los espacios agrarios, al incremento de los estándares de vida y el crecimiento de la población en las zonas urbanas. La totalidad de estos factores actúan para incrementar la demanda de recreación al aire libre, particularmente en destinos rurales, ya que la atractividad del campo para el turismo y la recreación están asociadas con la imagen de la ruralidad: naturaleza intacta y un auténtico modo de vida (Aznar et al., 2006). 
El turismo se asienta en espacios que estaban antes ocupados por la naturaleza, por grupos humanos o utilizados en otras actividades, como las agrícolas (Coll-Hurtado, 2016); esa dinámica de desarrollo conlleva implícitas transformaciones socioculturales y físicas para los territorios y sus comunidades (Pérez-Ramírez et al., 2011), que deterioran el ecosistema, transforman el espacio rural en un tejido denso de infraestructura y equipamiento para el turismo (Cruz-Coria et al., 2012). Las áreas rurales usadas para turismo se caracterizan ahora por el desarrollo de actividades e instalaciones que propician una reducción de la práctica agrícola, desarrollan aglomeraciones y fragmentación de los hábitat (Tapiador, 2008).

Estas implicaciones se pueden definir como el efecto o conjunto de efectos de diferente índole (Crosby y Prato, 2009), que resultan de la presión proveniente de la actividad turística, que se ejerce sobre territorios con riqueza patrimonial (Capel, 2016), expresada en términos del desarrollo de infraestructura, equipamiento e instalaciones (Cruz-Coria et al., 2012; Granados, 2008), así como de la presencia de turistas o visitantes, que se suscitan en un territorio rural determinado. Estos efectos engloban las acciones $u$ omisiones realizadas antes, durante y después del desarrollo de la actividad turística (Tabla 1).

El turismo que se desarrolla en contextos rurales posee fuertes vínculos con las cuestiones éticas y con la preservación de los recursos naturales (MacCannell, 2011), es decir, que aprovechar de manera equilibrada o sostenible los elementos de la naturaleza se traduce en una de las implicaciones más trascendentes en tales sitios, debido a que esos elementos son susceptibles de convertirse en rentables y de generar valor por medio de su utilización como espacio turístico, recreativo y de ocio (Niño-Gutiérrez et al., 2015), a través de las diversas modalidades turísticas. Otra de las implicaciones más sensibles se presenta cuando en los espacios considerados multifuncionales, la producción agrícola tiene que competir en el mercado de la tierra con otros usos no agrícolas, tales como la infraestructura e instalaciones turísticas, la vivienda para los nuevos habitantes o para turismo residencial, entre otros, con el consabido incremento de la renta y la especulación de la tierra (Zasada, 2011). Cuando esa competencia resulta adversa, provoca que los campesinos se vean presionados a vender sus tierras, por lo que los regímenes de propiedad se modifican. En el caso de México, las tierras ejidales tienen que convertirse en pequeña propiedad para transferirlas a un propietario no ejidal.

En la Tabla 1 se sintetizan las principales implicaciones que son identificadas en publicaciones especializadas, clasificadas en ambientales, económicas y sociales, evaluables tanto positiva como negativamente. 
Multifuncionalidad territorial y turismo. Implicaciones socioculturales, económicas y ambientales en destinos rurales emergentes. Un caso de estudio en Comala, Colima

Tabla 1. Implicaciones del turismo en los territorios rurales desde la perspectiva de la multifuncionalidad

\begin{tabular}{|c|c|c|}
\hline Ambientales & Económicas & Socioculturales \\
\hline $\begin{array}{l}\text { Conservación del paisaje y } \\
\text { protección de la biodiversidad }\end{array}$ & $\begin{array}{l}\text { Innovación y emprendimiento local } \\
\text { en diversos negocios turísticos }\end{array}$ & $\begin{array}{l}\text { Incorporación de jóvenes y } \\
\text { mujeres en actividades ligadas al } \\
\text { turismo }\end{array}$ \\
\hline $\begin{array}{l}\text { Ordenación de espacios y del uso } \\
\text { de sus recursos naturales }\end{array}$ & $\begin{array}{l}\text { Efecto multiplicador y mejora en la } \\
\text { distribución de la renta }\end{array}$ & $\begin{array}{l}\text { Conservación de las forma rural de } \\
\text { vida y cultura }\end{array}$ \\
\hline $\begin{array}{l}\text { Recuperación de espacios } \\
\text { naturales a través de procesos de } \\
\text { reforestación }\end{array}$ & $\begin{array}{l}\text { Diversificación de actividades } \\
\text { productivas y creación de empleo }\end{array}$ & Intercambios turistas/residentes \\
\hline $\begin{array}{l}\text { Estímulos para la conservación y } \\
\text { recuperación de espacios naturales }\end{array}$ & $\begin{array}{l}\text { La biodiversidad y la agricultura se } \\
\text { potencian y son rentables como } \\
\text { atractivos turísticos }\end{array}$ & $\begin{array}{l}\text { Valoración y aprovechamiento } \\
\text { de conocimientos locales y } \\
\text { conservación del legado cultural } \\
\text { (tradiciones, costumbres, } \\
\text { patrimonio histórico) }\end{array}$ \\
\hline $\begin{array}{l}\text { Creación de nuevas áreas naturales } \\
\text { protegidas }\end{array}$ & Posibilidad de atraer inversiones & $\begin{array}{l}\text { Influencia de los esquemas } \\
\text { culturales exteriores sobre los } \\
\text { locales }\end{array}$ \\
\hline $\begin{array}{l}\text { Introducción de medidas de } \\
\text { planificación y gestión }\end{array}$ & $\begin{array}{l}\text { No se garantiza la contribución del } \\
\text { turismo al desarrollo local }\end{array}$ & $\begin{array}{l}\text { Los campesinos se ven presionados } \\
\text { a vender sus tierras, por lo que } \\
\text { los regímenes de propiedad se } \\
\text { modifican }\end{array}$ \\
\hline $\begin{array}{l}\text { Alta demanda de paisajes } \\
\text { naturales/culturales, } \\
\text { Configuración/reconfiguración } \\
\text { del paisaje }\end{array}$ & $\begin{array}{l}\text { Tecnificación e industrialización de } \\
\text { actividades productivas }\end{array}$ & $\begin{array}{l}\text { Tensión social y resentimiento } \\
\text { hacia el turismo (turismo-fobia)/ } \\
\text { Incompatibilidades de valores } \\
\text { y prácticas entre visitantes y } \\
\text { residentes }\end{array}$ \\
\hline $\begin{array}{l}\text { Capacidad de carga física rebasada } \\
\text { por la presencia de multitudes }\end{array}$ & $\begin{array}{l}\text { La producción agrícola compite } \\
\text { en el mercado de la tierra con } \\
\text { otros usos no agrícolas: vivienda, } \\
\text { alojamiento, restaurantes, tiendas. } \\
\text { Terciarización de actividades } \\
\text { productivas }\end{array}$ & $\begin{array}{l}\text { Incremento de actividades } \\
\text { delictivas }\end{array}$ \\
\hline $\begin{array}{l}\text { Cambio de uso de suelo y procesos } \\
\text { de descentralización }\end{array}$ & $\begin{array}{l}\text { Incremento de la renta y } \\
\text { especulación, principalmente de } \\
\text { la tierra }\end{array}$ & $\begin{array}{l}\text { Desplazamiento o marginación } \\
\text { de ciertas actividades productivas } \\
\text { tradicionales y actores que antes } \\
\text { ocupaban un espacio central. }\end{array}$ \\
\hline $\begin{array}{l}\text { Desarrollo inmobiliario/urbano no } \\
\text { ligado al paisaje }\end{array}$ & $\begin{array}{l}\text { Urbanización difusa del territorio } \\
\text { rural }\end{array}$ & $\begin{array}{l}\text { Segregación/ gentrificación/ } \\
\text { fragmentación }\end{array}$ \\
\hline $\begin{array}{l}\text { Rivalidad por utilización de } \\
\text { recursos y suelo }\end{array}$ & $\begin{array}{l}\text { Concentración de ofertas e } \\
\text { infraestructuras que los vuelvan } \\
\text { atractivos }\end{array}$ & $\begin{array}{l}\text { Desculturización del destino e } \\
\text { imágenes estereotipadas }\end{array}$ \\
\hline $\begin{array}{l}\text { Intensidad de uso de los recursos } \\
\text { locales e incremento del volumen } \\
\text { de residuos, de tráfico y de ruido }\end{array}$ & $\begin{array}{l}\text { Estacionalidad de los empleos } \\
\text { y excesiva dependencia de la } \\
\text { actividad turística }\end{array}$ & $\begin{array}{l}\text { Cambios en valores, actitudes } \\
\text { y habilidades profesionales } \\
\text { requeridas }\end{array}$ \\
\hline
\end{tabular}

Fuente: Elaboración propia a partir de Cañada (2014), Crosby y Prato (2009), Marin (2015), Mason (2011), NiñoGutiérrez (2015), Ohe (2007), Sáez y Barrado (2008), Wall y Mathieson (2006). 


\section{TURISMO Y TERRITORIOS RURALES EN MÉXICO}

El turismo representa una actividad crucial para la economía de México y ha tenido un robusto desempeño en los últimos años, representando directamente el $8.5 \%$ del PIB y el $5.8 \%$ de empleo remunerado de tiempo completo (OCDE, 2017); sin embargo el modelo impulsado a nivel nacional se ha basado principalmente en el turismo de masas, dominado por inversiones extranjeras y que se apropia de grandes extensiones del territorio del que consume componentes naturales y culturales de gran valor, principalmente en ecosistemas costeros, para albergar hoteles y recibir aviones llenos de turistas, que dan paso a destinos de sol y playa. Pero también cuenta con turismo nacional o internacional que realiza viajes a pequeña escala, con presupuestos más reducidos, que ocupa pequeños alojamientos y busca un contacto más estrecho con las comunidades locales, con sus manifestaciones culturales y con la naturaleza (Coll-Hurtado, 2016), lo que se puede considerar como un turismo de baja intensidad o alternativo.

Al igual que en la mayoría de las regiones del mundo, el comportamiento del territorio rural en México durante los últimos años se caracteriza por una acelerada transición de la agricultura a otras actividades. Esto se reconoce por un incremento del ingreso y del empleo de las actividades no agropecuarias, como el turismo, incluso superando a algunas regiones urbanas (OCDE, 2007). Dicha diversificación de actividades ha posibilitado la mejora de las condiciones sociales y económicas en algunas zonas, pero también la disminución de las mismas en otras.

El turismo rural en México tiene sus orígenes, desde el marco normativo, en los años setenta del siglo XX, cuando apareció la concepción de ejido ${ }^{3}$ turístico, legitimado a través del artículo 144 de la Reforma Agraria, que establece que solamente los ejidos podrían explotar industrial y comercialmente los recursos no agrícolas ni forestales de los ejidos o comunidades (Garduño et al., 2009), aunque desde mucho tiempo antes existía el flujo de habitantes de las grandes zonas urbanas que buscaban dichos espacios en sus tiempos de ocio. Con el impulso del turismo, planteado como una alternativa de desarrollo económico, diversos grupos ejidales se han venido sumando a esta actividad y se les ha identificado como ejidos turísticos. Más adelante, cuando se da la modificación al artículo 27 de la Constitución Mexicana, que abre paso a la privatización de esos terrenos, los ejidos vuelven a sufrir cambios en su definición, ya no son únicamente propiedad social y la tenencia de la tierra se va reconfigurando de ejidal a privada.

En 1989, el Instituto Nacional Indigenista (INI), considerando el aprovechamiento de los beneficios del turismo, apoyó la creación de ocho proyectos de turismo en comunidades y pueblos indígenas (López-Pardo y Palomino-Villavicencio, 2008). Más tarde, a partir de la Cumbre de Río en 1992, se reconoció la importancia de incorporar los principios de la Agenda 21 a la práctica turística, por lo que la Organización Mundial del Turismo (OMT) convocó a sus miembros a aplicar los principios de la sostenibilidad a todas las formas de turismo en todos los tipos de destino (Ibid.).

3. Ejido es el nombre que recibe el modelo de distribución social de la propiedad rural en México (Kouri, 2015), es decir, que las tierras no son propiedad privada sino que pertenecen a un grupo social, aunque se asignan de manera equitativa a los integrantes de la comunidad. 
Diversos organismos y agencias internacionales como el Banco Interamericano de Desarrollo (BID), presentaron como propuesta al turismo rural, como una especie de panacea para promover la sostenibilidad y ayudar al abatimiento de pobreza (Barkin y Warnholtz, 2015), diversificar la oferta turística y propiciar crecimiento económico en las áreas rurales marginadas, que poseían atractivos para aprovechar a los consumidores de este espacio que estaban ávidos de conocer, experimentar y vivir el turismo rural (Garduño et al., 2009). A partir de esa premisa, en México se impulsaron las modalidades de turismo alternativo: ecoturismo, turismo rural y turismo de aventura. En esa década, el México rural tenía ya una transformación caracterizada por la reducción de la agricultura y el aumento de actividades no agropecuarias (de Grammont, 2005). Ello propició que las mayores oportunidades de desarrollo se dieran en éstas últimas, sobre todo cuando se observa que el ingreso de las familias rurales depende en un alto porcentaje de estas labores. Las actividades rurales no agropecuarias que sobresalen son la minería, el comercio al detalle, las manufacturas y ciertos servicios como el turismo.

En lo sucesivo, el tema de turismo rural empezó a figurar en los Planes Sectoriales del ramo, como una estrategia para la diversificación productiva y de desarrollo sostenible de las comunidades rurales, reconociendo el crecimiento del segmento de turistas cada vez más conscientes y que buscan destinos más auténticos (Diario Oficial de la Federación, 1996, 2002, 2008; Gobierno de la República, 2013). La afluencia de visitantes a los espacios rurales fue aumentando y con ello se improvisaron instalaciones y servicios por parte de sus pobladores, quienes vieron a los visitantes como una oportunidad para obtener nuevos ingresos. Lo anterior, provocó la generación de algunos programas por parte del gobierno para impulsar el denominado turismo rural. En esa inercia, a finales de 2006 se crea el Programa de Turismo Alternativo en Zonas Indígenas (PTAZI), a cargo de la Comisión Nacional para el Desarrollo de los Pueblos Indígenas (CDI), y se incorpora también como un eje de acción prioritario en la Agenda 21 para el Turismo Mexicano, impulsada por la Secretaría de Turismo Federal (SECTUR, 2008).

La gran riqueza biológica, geográfica, cultural y social que tiene México, ha fomentado la actividad turística en el medio rural. Este turismo denominado como alternativo, está sustentado en la naturaleza y su función escénica, donde el medio ambiente aporta los recursos para el uso del suelo y el mismo tiempo actúa como soporte de la actividad económica. Es así como en México la actividad turística incluye el paisaje y la ruralidad (Gómez-Merino et al., 2013), pero también implica, como argumentan Barkin y Warnholtz (2015, p. 201), un "sacrificio cultural", cuando trastoca formas tradicionales de organización -sociopolítica y económica-y compromete valores culturales locales.

Actualmente, diversas dependencias del gobierno mexicano como la CDI, la Comisión Nacional de Áreas Naturales Protegidas (CONANP), la Secretaria de Agricultura, Ganadería, Pesca y Alimentación (SAGARPA), la Secretaria de Desarrollo Social (SEDESOL), entre otras, bajo directrices de la Secretaria de Turismo (SECTUR), cuentan con recursos y programas de impulso al turismo en contextos rurales, como parte de las políticas nacionales de desarroIlo sostenible. No obstante, después de más de cuatro décadas, el turismo rural en México sigue siendo incipiente, los esfuerzos de las dependencias mencionadas son aislados y no 
se identifica una estrategia oficial ex profeso; recibe pocos apoyos económicos en comparación con el turismo de sol y playa, aunque también ha sido una alternativa para algunos espacios locales que ven a esta actividad como algo complementario a sus actividades agrarias.

\section{IMPLICACIONES TERRITORIALES DEL TURISMO EN COMALA, COLIMA. ANÁLISIS Y DISCUSIÓN DE RESULTADOS}

\subsection{Caracterización del área de estudio}

Comala es uno de los diez municipios del estado de Colima, su nombre significa lugar donde se hacen comales ${ }^{4}$ o lugar de comales, y deriva del náhuatl comalli, con el sufijo an (lugar). Está ubicado al norte de dicha entidad, con una extensión de 254 kilómetros cuadrados. Colinda al oeste con el municipio de Minatitlán, al este con el de Cuauhtémoc, y al norte con el estado de Jalisco (figura 1). En el municipio de Comala habitan 21.544 personas de las que $50,16 \%$ son mujeres y $41,75 \%$ se encuentran ocupados en los diferentes sectores económicos (INEGI, 2016). Además de la cabecera municipal, lugar donde reside la administración municipal y principal centro urbano, Comala está integrada por 18 comunidades consideradas rurales, entre las que destacan, por el tamaño de su población y su ascendencia indígena las de Suchitlán, La Nogalera y Cofradía de Suchitlán (de origen náhuatl), que se localizan al norte, y la de Zacualpán (de origen otomí), al oeste de la municipalidad. El estudio que se muestra en este trabajo se concentra las tres primeras, consideradas como la zona en que más negocios turísticos se están emprendiendo en las últimas dos décadas.

El municipio está asentado en una zona de transición entre ecosistemas de bosque mesófilo de montaña y de selvas medianas/bajas, por lo que el paisaje se encuentra dominado al norte por los volcanes Nevado de Colima y de Fuego (Eje Neo-volcánico), al oeste por las elevaciones que conforman la Sierra Madre del Sur y al sur, por el Valle de Colima (Ramírez-Ruiz y Bretón-González, 2016). En el estado predomina el clima cálido subhúmedo (86\%). Asimismo, en el $12,5 \%$ de su territorio se presenta clima seco y semi-seco. En las faldas del Volcán de Colima, la temperatura disminuye, por lo que presenta clima templado subhúmedo $(1,5 \%)$, aunque la temperatura media anual es de $25^{\circ} \mathrm{C}$ (ibid.).

Los principales atractivos naturales que se identifican son los paisajes que proyectan los volcanes Nevado de Colima y de Fuego, en cuyas estribaciones se ubica el "Parque Nacional Nevado de Colima" y la zona de protección forestal y refugio de la fauna silvestre "El Jabalí, esta última de propiedad privada. De igual forma, se aprecian como atractivos naturales las lagunas Carrizalillo y La María, los ríos La Barragana, Comala y la Lumbre, junto con las paisaje agrarios que contienen plantaciones de maíz, caña de azúcar y cría de ganado vacuno (Covarrubias y Conde, 2012).

4. El comal tradicional es un disco de barro que se ha utilizado desde las culturas prehispánicas para cocer tortillas de maíz y para tostar granos como el café o el cacao. Posteriormente se han hecho comales de metal. 

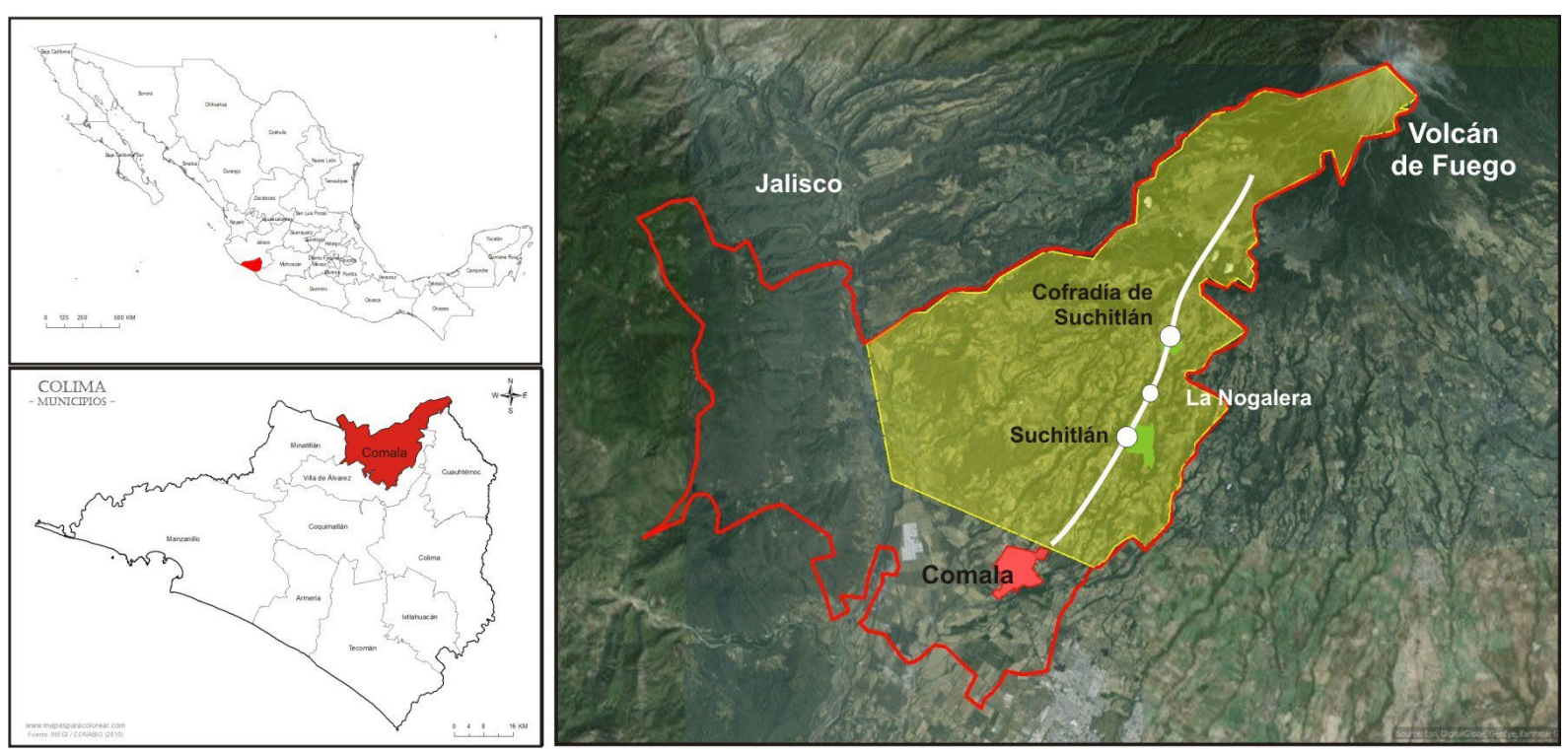

Figura 1. Localización del área de estudio

Fuente: Elaboración propia a partir de INEGI (2016) y Google Earth@

La riqueza cultural de la zona posee una gran influencia prehispánica debido a que forma parte de la región conocida como Culturas de Occidente (una de las áreas en que se dividió Mesoamérica) entre las que floreció la fase Comala, que se caracteriza por la belleza de su cerámica y las tumbas de tiro (Almendros y González, 2009). Diversas muestras de la cerámica de ese período se pueden observar en los museos de la zona. Las danzas (Los Morenos y Los Paspaques), máscaras tradicionales de madera, cestería, bordados y otras artesanías de gran colorido, son también representativas de manifestaciones culturales de las comunidades indígenas del municipio. Algunos de los edificios con valor histórico y cultural son el Palacio Municipal y el templo de San Miguel Arcángel, que se construyeron en torno a la plaza principal. La exhacienda de San Antonio, construida a finales del siglo XVIII en las faldas del volcán de Colima y la exhacienda de Nogueras, ubicada en la comunidad del mismo nombre.

Desde finales de la década de los 60, la zona urbana de Comala es identificada como el Pueblo Blanco de América, debido a que la fisonomía de sus calles estaba dominada por el color blanco de las fachadas de sus casas. En 1988, según Decreto Presidencial No. 25, del 30 de noviembre de ese año, se declara como zona de monumentos históricos en Comala, una área de 0,76 kilómetros cuadrados conformada por 51 manzanas que comprenden edificios con valor histórico y arquitectónico construidos entre los siglos XVI al XIX (Diario Oficial de la Federación, 1988). En septiembre de 2002 Comala fue incorporado al Programa de Pueblos Mágicos de México. Desde su inclusión, el turismo se ha planteado como una alternativa de desarrollo local, la actividad turística se ha incrementado y han surgido nuevos negocios, directos e indirectos al turismo, tanto en el centro histórico como en el resto del territorio municipal. En este rubro sobresalen los de alimentos y bebidas, que se caracterizan por la oferta de gastronomía típica de la región, establecidos en aquellos puntos de la geografía municipal donde hay un mayor flujo de visitantes. 
Aunque en realidad Comala se trata de un lugar muy diferente al escenario descrito en la novela de Juan Rulfo (1955), se debe reconocer que esta obra literaria ha influido en el posicionamiento del destino. Se puede decir que Pedro Páramo puso a Comala en el interés de visitantes nacionales y extranjeros (Covarrubias y Conde, 2012). Pero también, este fenómeno tiene su génesis en uno de los atractivos más fuertes del municipio de Comala conformado por el binomio clima-paisaje.

De acuerdo con el ciclo de evolución del área turística (Butler, 1980), el turismo en Comala se encuentra en una etapa de transición entre "involucramiento" y "desarrollo". La actividad turística en Comala es relativamente incipiente, su inicio se remonta a la década de los años setenta, cuando el Gobierno del Estado de Colima, a través de la entonces Dirección de Turismo, decidió desarrollar un centro turístico en el ejido Suchitlán para impulsar el turismo social, conocido popularmente como Centro Turístico Carrizalillo, debido a que el sitio donde se encuentra y su principal atractivo es precisamente la laguna que lleva ese nombre. Para ello, se le dotó de instalaciones de hospedaje, restaurante y comedores alrededor de la laguna. Fue fundado el 12 de diciembre de 1975. Posteriormente, un proyecto similar se llevó a cabo en la laguna La María. Sin embargo, durante más de veinte años se vivió un periodo (1980-2000) en el que no existió estrategia formal alguna para impulsar el turismo, hasta su reconocimiento como pueblo mágico.

A partir de indicadores de afluencia hotelera, el Gobierno del Estado de Colima (2017) reporta que durante 2016, Comala recibió 8.918 turistas. El área de mercado de este destino está definida por turistas nacionales, provenientes principalmente de las regiones Occidente y Centro de México, con incrementos importantes identificados en las temporadas vacacionales de verano, primavera (Semana Santa) e invierno. En menor medida, recibe visitantes de Estados Unidos de Norteamérica y Canadá. La mayoría de las facilidades turísticas aún son propiedad de locales. Para el registro de visitantes no existen mecanismos de conteo, a pesar de que durante las temporadas vacacionales, en las diversas ferias y eventos que se organizan a lo largo del año, se observa que el número de visitantes ha incrementado. El análisis obtenido durante los diversos recorridos realizados para observar las implicaciones del turismo en el territorio descrito, se puntualizan en los tres apartados siguientes.

\subsection{Implicaciones económico-productivas}

Tradicionalmente Comala ha destacado por su producción agrícola, principalmente maíz. Según la Delegación Estatal de SAGARPA, en 2010 Comala era líder estatal en la producción de ese grano y de ganado porcino (SAGARPA, 2011). Sin embargo, en las últimas dos décadas, el porcentaje de la población ocupada en el sector primario (agricultura, ganadería) ha disminuido de manera considerable. Ante lo poco atractivo que resulta producir alimentos, los campesinos han optado por actividades que les permitan mayores y más rápidos beneficios, incluso muchos de ellos han preferido vender sus terrenos (Alcántara y Chávez, 2006), para usos diversos como construcción de vivienda o instalaciones turísticas. Así mismo, se observa la introducción de nuevas prácticas agrícolas que se catalogan como industriales como granjas y procesadoras de carne de pollo y sus derivados, plantaciones de aguacates, caña de azúcar, zarzamora, arándano e invernaderos de tomate y otros vegetales, que se realizan de manera 
intensiva y extensiva. En la mayoría de estos casos se trata de inversiones provenientes de capital externo.

Estos hechos se pueden atribuir precisamente a la transición hacia la multifuncionalidad que ha experimentado el territorio y sus habitantes. Como se muestra en la Tabla 2, el porcentaje de personas ocupadas en el sector primario descendió más de un $20 \%$ en un lapso de 25 años, mientras que en los sectores comercio y servicios se incrementó notoriamente.

Tabla 2. Personas ocupadas según sector de actividad económica (porcentaje)

\begin{tabular}{|l|c|c|c|}
\hline \multicolumn{1}{|c|}{ Sector } & $\mathbf{1 9 9 0}$ & $\mathbf{2 0 0 0}$ & $\mathbf{2 0 1 5}$ \\
\hline Primario & 42,4 & 33,3 & 21,26 \\
\hline Secundario & 23,7 & 22,6 & 25,09 \\
\hline Comercio & 8,2 & 12,3 & 14,06 \\
\hline Servicios & 18 & 20,5 & 39,14 \\
\hline No especificado & ND & ND & 0,44 \\
\hline
\end{tabular}

Fuente: elaboración propia con datos de INEGI $(2000,2016)$

Como se ha venido describiendo, una de las principales actividades que más ha crecido en el sector terciario, es el turismo. Este crecimiento se pone de manifiesto con los datos aportados por la Dirección de Turismo y Desarrollo Económico del municipio, cuyos registros dan cuenta de 22 empresas vinculadas al turismo en 2002, año en que fue declarado Pueblo Mágico. 15 años más tarde, a finales del 2017, se tiene un registro de 175 establecimientos (Tabla 3) ubicados en diversos puntos de la geografía municipal. Los negocios señalados son representativos de los productos tradicionales de Comala, de manera específica los comedores que preservan la gastronomía típica así como los de pan dulce y de ponche, que se han convertido desde hace muchos años en productos que han dado fama a la localidad y se han posicionado como un atractivo y motivo de visita a la localidad, lo que significa una implicación positiva, ya que estas actividades económicas han favorecido la conservación de tradiciones.

Tabla 3. Establecimientos turísticos en el municipio de Comala-2017

\begin{tabular}{|l|c|}
\hline Alimentos y bebidas & 51 \\
\hline Tiendas de artesanías & 37 \\
\hline Guías de turistas & 23 \\
\hline Café tostado, molido y cafeterías & 21 \\
\hline Hospedaje & 21 \\
\hline Elaboración y venta de ponche & 16 \\
\hline Elaboración y venta de pan $\quad$ Total & 175 \\
\hline
\end{tabular}

Fuente: elaboración propia con información de la Dirección de Turismo y Desarrollo Económico del municipio de Comala, proporcionados en octubre 2017. 
El crecimiento de los establecimientos oferentes de alimentos y bebidas se atribuye a que los visitantes prefieren la sazón de las cocinas rurales, el clima fresco y el paisaje natural/ rural de ese zona. La mayoría de los negocios pertenecen a habitantes de las localidades inmediatas, lo que permite que todavía exista un control local y que el turismo esté generando beneficios económicos de manera directa.

\subsection{Implicaciones físico-ambientales}

Las implicaciones físico-ambientales en el territorio se observaron en dos vertientes principales: la producción agrícola industrial y el turismo. En primer lugar y en ambos casos, una de las más notorias a simple vista y de mayor alcance tiene que ver con el cambio de uso de suelo y la modificación de la cubierta vegetal, en los lugares cuya ocupación original era como espacio arbolado o producción de alimentos a pequeña escala, para dar paso a la producción agrícola industrial, a la urbanización mediante la construcción de casas (segunda residencia/turismo residencial), fraccionamientos campestres, caminos y calles en los espacios más atractivos de cada predio.

Las actividades agrícolas industriales se caracterizan por ser extensivas e intensivas, lo que significa que ocupan amplias superficies de terreno y consumen grandes cantidades de agua, que se traduce en pérdida de hábitat, erosión y uso de grandes cantidades de agroquímicos. Estas actividades requieren también de una amplia red de transporte de carga, lo que requiere de caminos y carreteras, provoca excesivo tránsito vehicular, emisiones a la atmósfera en forma de ruido y de $\mathrm{CO}_{2}$. Las producciones agrícolas industriales que reúnen un mayor número de los aspectos negativos señalados son el cultivo de caña de azúcar, la cría de ganado vacuno, porcino y aviar, los cultivos de aguacates, otras frutas y hortalizas como los tomates y algunas variedades de "berries" (arándanos y zarzamoras). En muchos casos se mantiene el riego con agua "rodada", es decir, que el agua corre por el suelo entre los surcos de los cultivos, regando las plantaciones pero arrastrando también parte del suelo. En otros casos se recurre a técnicas de control de maleza como el "acolchado", que se refiere al tendido de plásticos alrededor de las plantas para evitar el brote de la maleza. En muchos casos, los polímeros no se recogen y terminan mezclados con la misma tierra o con otros residuos agrícolas.

En el lado contrario de la moneda, se identificaron personas que están incursionando en la producción orgánica de hortalizas, la elaboración de composta y la cría de algunas especies pequeñas de animales como gallinas o conejos, a baja escala. Aunque se puede catalogar como incipiente, estos agricultores están comercializando sus productos a nivel local, incluyendo algunos restaurantes de la capital del Estado.

El auge turístico en la zona ha propiciado la presencia de emprendimientos de hospedaje, como el hotel Reserva La Cofradía, las cabañas El Fresnal y La Nogalera, sumándose a las ya existentes en las lagunas Carrizalillo y La María. En muchos de esos casos ha sido necesario efectuar cortes y movimiento de grandes cantidades de tierra en lomeríos y cerros para la construcción de instalaciones e infraestructura. Especial atención merece la edificación de cocinas rurales, cafeterías y comercios de artesanías y otros productos locales, que están proliferando a la orilla de las carreteras, cuya presencia ha modificado el paisaje, sobre todo el natural, debido a la edificación improvisada y desordenada de establecimientos precarios, 
construidos de manera heterogénea a partir de materiales como postes de madera, palapas, plásticos o láminas de cartón, y que, debido a la ausencia de una red de agua y drenaje en el sitio, presentan además claras deficiencias sanitarias y escaso manejo de los residuos sólidos generados por los prestadores de servicios y los visitantes.

La gestión del agua en los emprendimientos turísticos (extracción, suministro, consumo y post-consumo), cuenta con mínimos mecanismos de regulación y verificación. Las principales fuentes de suministro identificados son tres. En los lugares donde hay condiciones para el tendido de una red de distribución local (subterránea y superficial), el agua proviene de cuerpos superficiales como ríos y lagos o de pozos profundos perforados en propiedades comunes. Donde no existen condiciones para tal red, abundan las extracciones en pozos excavados en propiedades privadas, cuyo aprovechamiento es exclusivo de los propietarios. La disposición de aguas usadas se hace en fosas sépticas definidos de manejo o tratamiento, disposición de residuos sólidos a cielo abierto en barrancas u otros sitios similares, hasta la introducción de líneas de energía eléctrica de alta tensión de manera desordenada. En consecuencia, se observan amplias superficies erosionadas y pérdida del hábitat de la zona (Alcántara y Chávez, 2006).

\subsection{Implicaciones socio-culturales y político-administrativas}

Las comunidades que conforman la zona rural de Comala, históricamente han sufrido diversos problemas socio-culturales y político-administrativos, relacionados principalmente con la incertidumbre de la tenencia de la tierra, alcoholismo e insalubridad, enmarcados en un contexto de enormes carencias económicas, educativas y laborales que provocan un lento desarrollo. Uno de los puntos más críticos se observa en la comunidad de Suchitlán, que a su vez es uno de los territorios más representativos del municipio porque en él se asienta una de las comunidades indígenas de origen náhuatl más representativas del estado de Colima. En el contexto histórico y social, también es reconocido porque El Ejido Suchitlán fue decretado como tal en 1918, con una dotación de más de 3 mil hectáreas (Alcántara y Chávez, 2006), convirtiéndose así en el primer territorio convertido en propiedad social dentro del estado de Colima, aunque no se puede ocultar que su historia agraria está teñida de conflictos sociales sobre la tierra (Preciado, 2004), debido al traspaso o venta de terrenos sin documentos formales de por medio, lo que ha provocado la duplicidad de propietarios y superposición de títulos, con los subsecuentes reclamos de un mismo terreno por múltiples propietarios.

El primer acercamiento de estas comunidades con el turismo se dio, como ya se ha mencionado, a finales de los 70 del siglo pasado, con la construcción de los centros turísticos Carrizalillo y La María. Desde entonces y como en la mayoría de los casos, el turismo presenta una dualidad en su desempeño. Por un lado ha contribuido para que los habitantes que han incursionado en él tengan una alternativa económica, pero por otro, ha sido vector de problemas diversos.

De manera positiva y con especial énfasis, se hace referencia a los claros procesos de empoderamiento de las mujeres identificados durante la observación, específicamente en grupos de origen indígena, a efecto de su participación como empresarias en las cocinas rurales. Esta implicación positiva es muy evidente en la comunidad de la Nogalera, en la que 
existe un parador gastronómico liderado por mujeres. Antes de involucrarse en el turismo, muchas de estas mujeres enfrentaban situaciones de pobreza y de violencia, en una sociedad dominada por el sexo masculino. Ahora, a partir de que desempeñan actividades remuneradas, toman sus propias decisiones de sus negocios, de su familia y de su vida personal.

En otro orden de ideas, el auge del sector inmobiliario, impulsado por la demanda de terrenos para segunda residencia o instalaciones turísticas, está incrementando la venta de importantes extensiones de terrenos de origen ejidal, que se adquieren a precios muy bajos para venderse a precios mayores. Este fenómeno está suscitando una visible fragmentación del territorio rural que modifica el paisaje como resultado de la construcción de edificaciones tales como muros perimetrales que delimitan las nuevas propiedades, desarrollos conocidos como "campestres" que subdividen y venden lotes o viviendas en la modalidad de cotos así como casas de campo o ranchos que son usados únicamente los fines de semana o temporadas vacacionales. Las principales implicaciones sociales y políticas que se identifican suman de manera directa a los conflictos por la tenencia de la tierra ya existentes, pero también están cambiando la configuración del régimen de propiedad al pasar de ejidal a privada, lo que se traduce en que los locales ya no son propietarios de esos terrenos, los nuevos propietarios provienen de otras localidades. Estos sucesos están incrementando los precios de los terrenos así como la especulación para futuros usos y ventas de los espacios. La suma de estas implicaciones puede acarrear efectos de segregación e incluso de gentrificación.

Otro hecho que suma a estas implicaciones es la presencia de establecimientos apostados en los márgenes de las carreteras, cuyo principal conflicto es que ocupan un espacio considerado como propiedad pública, que se convierte, en consecuencia, en un uso ilegal pero tolerado por la autoridad. En respuesta a esa conducta, otros miembros de la comunidad pretenden realizar la misma práctica, argumentando la existencia de los primeros.

\section{CONCLUSIONES}

La construcción del marco teórico y conceptual ha permitido identificar que las nociones de MFR y post-productivismo se han estudiado de manera más amplia en el contexto europeo, y la nueva ruralidad, en América Latina. Sin embargo, se ha registrado también una amplia convergencia sobre sus significados y propósitos. De manera general, se concluye que estos términos se enmarcan en la necesidad de contar con una epistemología que contribuya a describir y denominar el proceso de transformación que se han venido dando en el mundo rural, tras la puesta en valor de nuevas funciones productivas (mercadeables) y servicios ecosistémicos (no mercadeables) que el campo está desempeñando. Se identifica también un profuso debate que origina múltiples aportaciones académicas en las que se da cuenta de estudios teóricos y empíricos, promotores de una amplia polisemia, surgida del ejercicio que cada autor en particular realiza con el afán de perpetuar conceptos agudos y diferentes, desde la perspectiva de su campo de interés. En ese debate, se confirma también que el turismo en contextos rurales es una de las nuevas funciones de ese medio, y que presenta una dualidad en sus implicaciones.

En el trabajo empírico, la radiografía del caso de Comala ilustra dos conclusiones fundamentales: en primer lugar, se hace evidente que en todo su territorio se están viviendo 
nuevos procesos socio-culturales, económicos, políticos y ambientales, cuyas características se pueden relacionar con lo establecido en las teorías analizadas. De esas aseveraciones, se observa que el turismo se ha insertado como una nueva función y a la vez, está generando otras nuevas funciones en el territorio, tales como expendios de gasolina, farmacias, tiendas de conveniencia. Desde esa óptica, la multifuncionalidad en la zona muestra claro-oscuros importantes, por ejemplo, ha diversificado las opciones de ingresos para algunos habitantes pero también han llegado nuevos actores económicos ajenos a la comunidad.

En segundo lugar, que el desarrollo y crecimiento del turismo en ese municipio se ha basado en la ausencia de mecanismos de gestión sostenible del territorio o de instrumentos de planificación, de manera que ha ido ganando, de forma anárquica, espacios de gran valor natural o que originalmente estaba destinado a otras funciones. En consecuencia, esta actividad se encuentra asociada a importantes procesos de transformación de la zona estudiada y mantiene un proceso de expansión que lo está convirtiendo en una de las principales actividades económicas, pero también está generando modificaciones drásticas en el uso de los territorios y sus recursos, de sistemas productivos y de sustento tradicionales, de reacomodos en los sistemas de propiedad de la tierra y ubicación de las viviendas de los locales, aunado a la presencia de agroindustria y al desarrollo inmobiliario. Desde esas consideraciones, se observa que las nuevas funciones del territorio rural se pueden traducir en un proceso negativo, si se considera que surgen de las presiones económicas, políticas y socioculturales de algunos grupos de poder, lo que propicia cambios en los sistemas tradicionales de uso de los territorios de la zona rural de Comala.

Apuntando a propuestas estratégicas que pueden incorporarse para minimizar las implicaciones del turismo en la zona rural, se concluye que se puede inducir un modelo de desarrollo estratégico del territorio, que permitan conservar el patrimonio biocultural, con el propósito de lograr un turismo más controlado. Este enfoque requiere de la sensibilización y concienciación de las partes involucradas: habitantes, autoridades locales, empresarios y turistas. De igual forma, se deben diseñar y poner en práctica instrumentos de gestión sostenible tales como políticas y reglamentos que eviten la excesiva subdivisión de predios y el cambio de uso de suelo. Parte de las iniciativas pueden enfocarse a políticas para el establecimiento de nuevos negocios turísticos que consideren, entre otros criterios, el diseño de productos turísticos que sean técnica, financiera y ambientalmente viables, con el propósito de construir un desarrollo sostenible a través del turismo.

\section{REFERENCIAS BIBLIOGRÁFICAS}

Acevedo-Osorio, Á. (2016). Monofuncionalidad, multifuncionalidad e hibridación de funciones de las agriculturas en la cuenca del río Guaguarco, sur del Tolima. Luna Azul, 43, 251-285. http://doi.org/10.17151/luaz.2016.43.12

Alcántara, T. J., \& Chávez, M. E. (2006). Cambios recientes en la propiedad social en la zona metropolitana de Colima. El caso de los ejidos Comala, Suchitlán, El Pedregal y Nogueras. Palapa. Revista de Investigación Científica En Arquitectura, 1(1), 25-36. 
Allsop, D., Allen, H., Clare, H., Cook, I., Raxter, H. \& Upton, C. (2010). Ethnography and participant observation. In Gomez, B. \& Jones III, J. P. Research Methods in Geography (p. 206-). Chichester, UK: Wiley-Blackwell.

Almendros, L., \& González, F. (2009). El occidente de México. La reocupación del valle de Colima. Boletín Americanista, Año LIX, No 59, 137-154. http://revistes.ub.edu/index. php/BoletinAmericanista/article/download/13192/16531

Armesto, X. A. (2005). Notas teóricas en torno al concepto de postproductivismo agrario. Investigaciones Geograficas, (36), 137-156. Retrieved from http://rua.ua.es/dspace/ bitstream/10045/275/3/Armesto\%20Lopez-Notas\%20teoricas.pdf

Ávila, H. (2005). Lo urbano-rural, ¿Nuevas expresiones territoriales? Cuernavaca, Morelos: Centro Regional de Investigaciones Multidisciplinarias/UNAM CRIM. Retrieved from https://www.crim.unam.mx/web/sites/default/files/Lo\%20urbano\%20rural.pdf

Ávila, H. (2015). Tendencias recientes en los estudios de Geografía rural. Desarrollos teóricos y líneas de investigación en países de América Latina. Investigaciones Geograficas, 2015(88), 75-90. http://doi.org/10.14350/rig.44603

Aznar, O., Marsta, J.-B., \& Rambonilaza, T. (2006). Tourism and landscape within multifunctional rural areas, the french case. In Mander, U., Wiggering, H., \& Helming, K. (Eds). Multifunctional Land Use: Meeting Future Demands for Landscape Goods and Service. (pp. 293-303). Berlin: Spinger.

Banco Mundial y FAO. (2003). La nueva ruralidad en Europa y su interés para América Latina. Roma, Italia.

Barkin, D., \& Warnholtz, G. (2015). Ecoturismo : una quimera para comunidades rurales en áreas naturales protegidas. Otra Economía, 9(17), 199-209. http://doi.org/10.4013/ otra.2015.917.08

Bassi, I., \& De Poi, P. (2010). Measuring multifunctional (agritouristic) characterization of the territory. In 116TH EAAE SEMINAR "Spatial Dynamics in Agri-food Systems: Implications for Sustainability and Consumer Welfare" (pp. 1-12). European Association of Agricultural Economists (EAAE). Retrieved from http://ageconsearch.umn.edu/record/94927/files/ paper completo 19.pdf

Bergstrom, J. C. (2005). Postproductivism and changing rural land use values and preferences. In Goetz, S. J:, Shortle, J. S. \& Bergstrom, J. C. Land use problems and conflicts : causes, consequences and solutions (pp. 50-59). London \& New York: Routledge, Taylor \& Francis Group. http://doi.org/10.4324/9780203799833

Borrelli, I. P. (2016). Territorial Sustainability and Multifunctional Agriculture: A Case Study. Agriculture and Agricultural Science Procedia, 8, 467-474. http://doi.org/10.1016/i. aaspro.2016.02.046

Brouwer, F., \& van der Heide, M. (2009). Multifunctional rural land management. Economics and policies (First). UK: Earthscan.

Butler, R. (1980). The Concept of a tourist area cylce of evolution: implications for management of resources. Canadian Geographer, XXIV(1), 5-12. http://doi. org/10.1111/i.1541-0064.1980.tb00970.x

Cañada, E. (2014). Implicaciones socioambientales de la construcción del espacio turístico. Ecología Política, (2009), 12-16. 
Capel, H. (2016). Las ciencias sociales y el estudio del territorio. Revista Bibliográfica de Geografía Y Ciencias Sociales, XXI(1149).

César-Dachary, A., \& Arnaiz-Burne, S. M. (2006). Territorio y Turismo. Nuevas dimensiones y acciones. Puerto Vallarta, Jalisco: Universidad de Guadalajara.

Coll-Hurtado, A. (2016). Espacio y ocio: El turismo en México. Ciudad de Méxcio: UNAM, Instituto de Geografía.

Covarrubias, R., \& Conde, E. M. (2012). El turismo como herramienta del desarrollo municipal. El caso Comala, Colima. In Osorio, M., López, Al. (Coords). Investigación Turística. Hallazgos y aportaciones. (pp. 233-248). México: SECTUR, UAEM, UNAM, AMIT.

Crosby, A., \& Prato, N. (2009). Los sistemas del turismo rural: elementos económicos, sociales ambientales. In Crosby, A. (Ed). Re-inventando el turismo rural. Gestión y desarrollo (pp. 51-82). Barcelona: LAERTES.

Cruz-Coria, E., Zizumbo-Villarreal, L., Cruz-Jiménez, G., \& Quintanilla-Montoya, A. L. (2012). Las dinámicas de dominación capitalista en el espacio rural: la configuración de paisajes turísticos. Cuadernos de Desarrollo Rural, 9(69), 151-174.

de Grammont, H. C. (2004). La nueva ruralidad en América Latina. Revista Mexicana de Sociología, 66(Número especial), 279-300. Retrieved from http://www.jstor.org/ stable/3541454?seq=1\#page scan tab contents

de Grammont, H. C. (2005). Prólogo. In Ávila-Sánchez, H. Lo urbano-rural, ¿nuevas expresiones territoriales? (pp. 11-18). Cuernavaca, Morelos, México: UNAM-CRIM. Retrieved from http://bibliotecavirtual.clacso.org.ar/Mexico/crim-unam/20100503120801/Lo urbano rural.pdf

Diario Oficial de la Federación. Decreto por el que se declara una zona do monumentos históricos en la población de Comala, Estado de Colima, con el perímetro, características y condiciones a que se refiere este Decreto, Pub. L. No. 30/11/1988 (1988). México. Retrieved from http://www.dof.gob.mx/nota_detalle.php?codigo=4793335\&fecha=30/11/1988

Diario Oficial de la Federación. Programa de Desarrollo del Sector Turismo 1995-2000 (1996). México. Retrieved from www.dof.gob.mx

Diario Oficial de la Federación. Programa Nacional de Turismo 2001-2006. Al (2002). México. Retrieved from www.dof.gob.mx

Diario Oficial de la Federación. Programa Sectorial Turismo 2007-2012 (2008). México. Retrieved from http://www.ordenjuridico.gob.mx/Documentos/Federal/wo148.pdf

Dirven, M., Perico, R. E., Sabalain, C., Baeza, D. C., \& Faiguenbaum, S. (2011). Hacia una nueva definición de "rural" con fines estadísticos en América Latina. Santiago de Chile: CEPAL.

Dissart, J.-C., \& Marcouiller, D. W. (2012). Rural Tourism Production and the ExperienceScape. Tourism Analysis, 17(6), 691-704. http://doi.org/10.3727/1083542 $\underline{12 X 13531051127104}$

Echeverri, R., \& Ribero, M. P. (2002). Nueva ruralidad: Visión del territorio en América Latina y el Caribe. Instituto Interamericano de Cooperación para la Agricultura IICA, Centro Internacional de Desarrollo Rural CIDER, Corporación Latinoamericana Misión Rural. Retrieved from http://repiica.iica.int/docs/B0536e/B0536e.pdf

Evans, N. (2001). Reflexiones en torno al modelo productivista de la agricultura y la ganadería. In García Pascual, F. (Coord). El mundo rural en la era de la globalización: incertidumbres y potencialidades. Serie Estudios No. 146. X Coloquio de Geografía Rural de España de 
la Asociación de Geógrafos Españoles. (pp. 45-64). Madrid: Ministerio de Agricultura, Pesca y Alimentación, Universidad de Lleida.

Fagioli, F., Rocchi, L., Paolotti, L., Roman, S., \& Boggi, A. (2017). From the farm to the agri-food system: A multiple criteria framework to evaluate extended multi-functional value. Ecological Indicators, 79(April), 91-102. http://doi.org/10.1016/j.ecolind.2017.04.009 FAO (1999). El caracter multifuncional de la agricultura y la tierra. Documento expositivo., 61. Garduño, M., Guzmán, C., \& Zizumbo, L. (2009). Turismo rural : Participación de las comunidades y programas federales. El Periplo Sustentable, (17), 5-30. Retrieved from http:// www.redalyc.org/articulo.oa?id=193414420001

Gobierno de la República. Programa Sectorial de Turismo 2013-2018 (2013). México. http:// doi.org/10.1073/pnas.0703993104

Gobierno del Estado de Colima. (2017). Segundo Informe de Gobierno. Anexo Estadístico Tomo I. Colima, Col.

Gómez-Mendoza, J. (2001). Las "nuevas" funciones socioeconómicas y medioambientales de los espacios rurales. In García Pascual, F. (Coord). El mundo rural en la era de la globalización: incertidumbres y potencialidades. Serie Estudios No. 146. X Coloquio de Geografía Rural de España de la Asociación de Geógrafos Españoles. (pp. 111-148). Madrid: Ministerio de Agricultura, Pesca y Alimentación, Universidad de Lleida.

Gómez-Merino, F. C., García-Albarado, J. C., Trejo-Téllez, L. I., Morales-Ramos, V., GarcíaGarcía, C. G., \& Pérez-Sato, J. A. (2013). Paisaje y turismo rural en México : fortalezas y desafíos para su potenciación. Revista Mexicana de Ciencias Agrícloas, (5), 1027-1042. Retrieved from http://www.redalyc.org/articulo.oa?id=263128352014

Gómez-Pellón, E. (2015). Aspectos teóricos de las nuevas ruralidades latinoamericanas. Gazeta de Antropologia. Revista de Antropología Cultural, 11(0214-7564), 1-15. Retrieved from http://www.gazeta-antropologia.es/?p=4770

Gómez, S. (2001). ¿Nueva ruralidad? Un aporte al debate. Estudos Sociedade E Agricultura, 17, 5-32. Retrieved from https://www.google.com/ url? sa $=t \& r c t=j \& q=\&$ es $r c=s \&$ source $=$ web \& $c d=1 \& v e d=0$ ahUKEwis $b-377 b A-$ hXHUBQKHQnNBAoQFggnMAA\&url=https\%3A\%2F\%2Frevistaesa. com\%2FV3\%2Fojs-3.1.1\%2Findex.php\%2Fesa\%2Farticle\%2Fdownload\%2F196\%2F192\%2F\&usg=AOvVaw3JWUmEBfOJbwef2ZduibST

Granados, V. (2008). La gestión sostenible del territorio como elemento clave para el desarrollo turístico. In Conferencia Internacional de Turismo, El conocimiento como valro diferencial de los destinos tur'siticos. Malaga, España.

Hernández, M. (2009). Multifunctionality of rural environments. Between utopia and reality. In Frutos, L. M:; Climent, E.; Ruíz, E.; Bicalcho A. M., \& Laurens, L. New Ruralities and Sustainable Use of Territory (pp. 333-348). Zaragoza, España: Prensas Universitarias de Zaragoza.

Ilbery, B. (1998). Dimensions of Rural Change. In Ilbery, B. (Ed). The Geography of Rural Change. London \& New York: Routledge, Taylor \& Francis Group.

Ilbery, B., \& Bowler, I. (1998). From agricultural productivism to post-productivism. In Ilbery, B. (Ed). The Geography of Rural Change (pp. 57-84). New York: Routledge, Taylor \& Francis Group. 
Multifuncionalidad territorial y turismo. Implicaciones socioculturales, económicas y ambientales en destinos rurales emergentes. Un caso de estudio en Comala, Colima

INEGI (2000). Perfil Sociodemográfico Colima. XII Censo General de Poblacion y Vivienda 2000. Aguascalientes, Ags.: INEGI.

INEGI (2016). Anuario estadístico y geográfico de Colima 2016. Aguascalientes, Ags.: INEGI, Gobierno del estado de Colima.

Ivars, J. A. (2000). Turismo y espacios rurales: conceptos, filosofías y realidades. Investigaciones Geográficas, (23), 59-88. Retrieved from http://www.cervantesvirtual.com/nd/ ark:/59851/bmczw1v4

Jay, M. (2004). Productivist and Post-productivist Conceptualisations of Agriculture from a New Zealand Perspective. Glimpes of a Gaian World, Essays in Honour of Peter Holland, 151-170.

Jean, B. (1987). La question rurale: la ruralité et sa sociologie par. Recherches Sociologiques, 20(3), 287-310. Retrieved from https://sharepoint.uclouvain.be/sites/rsa/ Articles/1989-XX-3 05.pdf

Jennings, G. (2010). Tourism Research (2nd ed.). Australia: WILEY.

Kay, C. (2001). El paradigma del desarrollo rual en América Latina. In García Pascual, F. (Coord). El mundo rural en la era de la globalización: incertidumbres y potencialidades. Serie Estudios No. 146. X Coloquio de Geografía Rural de España de la Asociación de Geógrafos Españoles. (pp. 337-430). Madrid: Ministerio de Agricultura, Pesca y Alimentación, Universidad de Lleida.

Kay, C. (2009). Estudios rurales en América Latina en el periodo de globalización neoliberal: ¿una nueva ruralidad? Revista Mexicana de Sociología, 71(4), 607-645.

Knickel, K., \& Renting, H. (2000). Methodological and Conceptual Issues in the Study of Multifunctionality and Rural Development. Sociologia Ruralis, 40(4), 512-528.

Kouri, E. (2015). La invención del ejido. Nexos, on Line. Retrieved from https://www.nexos. com.mx/?p=23778

Kramkowski, V., \& Mulvihill, P. (2017). Emerging dynamics of environmental governance in northern post-productivist regions. Local Environment, 22(3), 350-364. http://doi.org/ $10.1080 / 13549839.2016 .1205570$

Ledesma, F. (2014). La multifuncionalidad del medio rural en España: experiencia de desarrollo territorial rural en Andalucía. Estudios Agrarios, (57), 183-198. Retrieved from http:// www.pa.gob.mx/publica/rev 57/analisis/la multifuncionalidad Fermin ledesma.pdf

Llambi, L. (2012). Procesos de transformación de los territorios rurales latinoamericanos: los retos de la interdisciplinariedad. EUTOPÍA, (3), 117-134.

López-Pardo, G., \& Palomino-Villavicencio, B. (2008). Políticas públicas y ecoturismo en comunidades indígenas de México. Teoría Y Praxis, (5), 33-50.

MacCannell, D.-- (2011). The Ethics of Sightseeing. Berkeley, CA. USA: University of California Press.

Marín, G. (2015). Sin tierras no hay Paraíso. Turismo, organizaciones agrarias y apropiación territorial en México: una introducción. In Marín, Guardado Gustavo (Coord). Sin tierras no hay Paraíso. Turismo, organizaciones agrarias y apropiación territorial en México. (p. 306). Tenerife, España.: Pasos, Revidsta de Turismo y Patrimonio Cultural.

Martínez, E. (2002). La Multifuncionalidad del Mundo Rural. Revistas ICE Globalización Y Mundo Rural, (803), 33-44. Retrieved from http://www.revistasice.com/CachePDF/ ICE $803 \quad 33-44$ C269640516020DF2E9AB5950BAB97D37.pdf 
Mason, P. (2011). Tourism Impacts, Planning and Manegement. New York: Routledge.

Méndez, M. (2005). Contradicción, complementariedad e hibridación en las relaciones entre lo rural y lo urbano. In Ávila-Sánchez, H. Lo urbano-rural, ¿nuevas expresiones territoriales? Cuernavaca, Morelos: UNAM, Centro Reginal de Investigaciones Multidisciplinarias.

Monterroso, N., \& Zizumbo, L. (2009). La reconfiguración neoliberal de los ámbitos rurales a partir del turismo: ¿Avance o retroceso? Convergencia. Revista de Ciencias Sociales, (50), 133-164.

Moreno, A. (2017). Explorando el significado cultural de la Nueva Ruralidad en Castilla y León: Un caso de estudio inexplorado. Chungara, Revista de Antropología Chilena, 49(2), 279-294. http://doi.org/10.4067/S0717-73562017005000008

Niño-Gutiérrez, N. S., Segrelles, J. A., Niño-Castillo, I. N., \& Niño-Castillo, J. E. (2015). Multifuncionalidad y turismo en el Parque Natural "El Hondo" de la comunidad valenciana. El Periplo Sustentable, (9), 34-56. Retrieved from http://rperiplo.uaemex.mx/

Nogar, A. G. (2007). La multifuncionalidad territorial como escenario de la nueva ruralidad. Pampa: Revista Interuniversitaria de Estudios Territoriales, (3), 27-41. Retrieved from http://dialnet.unirioja.es/servlet/articulo?codigo $=2756282$

OCDE (2007). Estudios de Política Rural: México. (Organización para la Cooperación y el Desarrollo Económico OCDE, Ed.) (Español). México: Secretaría de Agricultura, Ganadería, Desarrollo Rural, Pesca y Alimentación (SAGARPA), Instituto Nacional para el Desarrollo de Capacidades del Sector Rural, A.C. (INCA Rural). Retrieved from http:// www.oecd.org/centrodemexico/medios/39076610.pdf

OCDE (2017). Estudio de la Política Turística de México. Resumen Ejecutivo, Evaluación y Recomendaciones.

Ohe, Y. (2007). Multifunctionality and rural tourism: a perspective on farm diversification. Journal of International Farm Management, 4(1), 1-23.

ONU-HABITAT (2009). Informe Mundial Sobre Asentamientos Humanos 2009. Por un mejor futuro urbano. Retrieved from http://mirror.unhabitat.org/documents/GRHSO9/ K0952834s.pdf

Paracchini, M. L., Correia, T. P., Loupa-ramos, I., Capitani, C., \& Madeira, L. (2016). Land Use Policy Progress in indicators to assess agricultural landscape valuation: how and what is measured at different levels of governance. Land Use Policy, 53, 71-85. http://doi. org/10.1016/i.landusepol.2015.05.025

Pérez-Ramírez, C., Zizumbo-Villarreal, L., Romero-Contreras, T., Cruz-Jiménez, G., \& MadrigalUribe, D. (2011). El turismo como intervención e implicaciones para las comunidades rurales. Gestión Turística, (16), 229-264. Retrieved from http://www.redalyc.org/articulo.oa?id=223322452011

Pérez, E. (2001). Hacia una nueva visión de lo rural. In ¿Una nueva ruralidad en América Latina? (pp. 17-29). Buenos Aires: CLACSO, Consejo Latinoamericano de Ciencias Sociales. Retrieved from http://bibliotecavirtual.clacso.org.ar/clacso/gt/20100929011414/2perez.pdf

Plaza-Gutiérrez, J. I. (2006). Territorio, Geografía Rural y Políticas Públicas. Desarrollo y Sustentabilidad. Boletin de Las A.G.E., (41), 69-95. Retrieved from https://dialnet.unirioja.es/descarga/articulo/1958883.pdf 
Preciado, J. (2004). Historia agraria en el ejido de Suchitlan, Colima. Sociedades Rurales, Producción Y Medio Ambiente, 5(8), 95-106. Retrieved from http://132.248.9.34/ hevila/Sociedadesruralesproduccionymedioambiente/2004/vol5/no8/7.pdf

Ramírez-Ruiz, J. J., \& Bretón-González, M. (2016). Fisiografía y geología. In La biodiversidad en Colima. Estudio de estado. (1st ed., pp. 25-31). Mexico, DF: Comisión Nacional para el Conocimineto y Uso de la Biodiversidad CONABIO.

Ratier, H. (2002). Rural, ruralidad, nueva ruralidad y contraurbanización. Un estado de cuestión. Revista de Ciencias Humanas, Florianápolis, (31), 9-29. Retrieved from https:// periodicos.ufsc.br/index.php/revistacfh/article/viewFile/25175/22145

Ribeiro, N., \& Foemmel, E. (2012). Participan Observation. In Dwyer, L., Gill, A., Seetaram, N. (Eds) Handbook of Research Methods in Tourism. Quantitative and Qualitative Approaches. (p. 377-). Cheltenham, Uk.: Edward Elgar Publishing Limited.

Ricart, S. (2016). Entre la multifuncionalitat i la legitimitat social de l'agricultura: Un estat de la qüestió. Documents d'Analisi Geografica, 62(1), 161-181. http://doi.org/10.5565/rev/ dag. 273

Rivas, Á., \& Quintero, H. (2014). Reappraising the multiple functions of traditional agriculture within the context of building rural development investigative skills. Agronomía Colombiana, 32(1), 130-137. http://doi.org/10.15446/agron.colomb.v32n1.40185

Rodríguez, J. J., Uribe, A., \& Reyes, F. E. (2011). Competitividad rural: el caso de la región de los Valles, frente a una integración regional. Revista Fuente, 3(9), 98-113. Retrieved from http://fuente.uan.edu.mx/publicaciones/03-09/7.pdf

Rosas-Baños, M. (2009). Una contribución a la Economía Ecológica: actividades No-proletarias generadoras de ingresos. Universidad Autónoma Metropolitano.

Rosas-Baños, M. (2013). Nueva Ruralidad desde dos visiones de progreso rural y sustentabilidad: Economía Ambiental y Economía Ecológica. Polis Revista Latinoamericana (En Línea), (34), 1-16. Retrieved from http://polis.revues.org/8846

Rovai, M., \& Andreoli, M. (2016). Combining Multifunctionality and Ecosystem Services into a Win-Win Solution. The Case Study of the Serchio River Basin (Tuscany - Italy). Agriculture, 6(4), 1-25. http://doi.org/10.3390/agriculture6040049

Rubio, B. (2006). Territorio y globalización en México: ¿un nuevo paradigma rural? Comercio Exterior, 56(12), 1047-1054. Retrieved from http://revistas.bancomext.gob.mx/rce/ magazines/98/3/RUBIO globalizacion.pdf

Rubio, P. (1999). El postproductivismo en los espacios rurales. In Galdós, R. y Ruíz Urrestarazu, E. (Eds). Postproductivismo y medio ambiente. Informes Técnicos del Departamento de Agricultura y Pesca del País Vasco No. 82 (pp. 17-77). Vitoria-Gasteiz: Servicio Central de Publicaciones del Gobierno Vasco.

Ruiz Rivera, N., \& Delgado Campos, J. (2008). Territorio y nuevas ruralidades: un recorrido teórico sobre las transformaciones de la relación campo-ciudad. EURE, XXXIV(102), 77-95. Retrieved from http://www.redalyc.org/articulo.oa?id=19610205

Rulfo, J. (1955). Pedro Páramo. México: Fondo de Cultura Económica.

Sáez, A., \& Barrado, D. (2008). La Dehesa: un espacio multifuncional para un aprovechamiento turístico diversificado. In Ivars Baidal, J. A. Vera Rebollo, J. F. (Eds). Espacios turísticos. Mercantilización, paisaje e identidad. Alicante, España: Editorial Agua Clara, SL., Universitat d'Alicant. 
Santana-Aispuro, E. (2014). Multifuncionalidad y tranformaciones en el territorio de la microcuenca de Tapalpa, Jal. Universidad de Guadalajara, Centro Universitario de la Costa Sur. Retrieved from http://148.202.105.18/websecgral/sites/archivos/acuerdo/2007acuerdorg01.pdf

SECTUR (2008), Agenda 21 para el Turismo Mexicano. México.

Segrelles, J. A. (2008). Multifuncionalidad Rural : ¿Un Nuevo Modelo De Desarrollo o una estrategia de la UE para prescindir de la agricultura? Universiad de Alicante.

Segrelles, J. A. (2007). La multifuncionalidad rural: realidad conflictiva en la Unión Europea, mito en América Latina. Ería, 72, 89-99.

Sepúlveda, S. (2008). Gestión del desarrollo sostenible en territorios rurales: métodos para la planificación. San José, Costa Rica: IICA.

Silva, R. (2010). Multifuncionalidad agraria y territorio. Algunas reflexiones y propuestas de análisis. EURE, 36(109), 5-33.

Tapiador, F. (2008). Rural Analysis and Management. An Earth Science Approach to Rural Science. Toledo, Spain: Springer. http://doi.org/10.1007/978-3-540-73343-0

Trpin, V. (2005). El desarrollo rural ante la nueva ruralidad. Algunos aportes desde los métodos cualitativos. AIBR. Revista de Antropología Iberoamericana, (42), 1-16. Retrieved from http://www.redalyc.org/pdf/623/62304207.pdf

Veal, A. J. (2006). Research Methods for Leisure and Tourism. A practical guide. Great Britain: Prentice Hall, FINANCIAL TIMES.

Vilchis-Onofre, A., Zizumbo-Villarreal, L., Monterrosos-Salvatierra, N., Arriaga-Álvarez, E., \& Palafox-Muñoz, A. (2016). Dinámicas capitalistas para la acumulación por despojo. Revista Ciencias Sociales, 2016(I), 31-41.

Wall, G., \& Mathieson, A. (2006). Tourism: Change, Impacts, and Opportunities. Essex, England: PEARSON Education. Retrieved from http://books.google.com/ books?id=jisvN9N9aesC\&pgis=1

Wilson, G. A. (2001). From productivism to post-productivism....and back again? Exploring the (un) changed natural and mental landscapes of European. Transactions of the Institute of British Geographers, 26, 77-102. http://doi.org/10.1111/1475-5661.00007

Wilson, G. A. (2009a). Post-Productivist and Multifunctional Agriculture. International Encyclopedia of Human Geography, 379-386. http://doi.org/10.1016/ B978-008044910-4.00895-6

Wilson, G. A. (2009b). The spatiality of multifunctional agriculture: A human geography perspective. Geoforum, 40(2), 269-280. http://doi.org/10.1016/j.geoforum.2008.12.007

Zasada, I. (2011). Multifunctional peri-urban agriculture-A review of societal demands and the provision of goods and services by farming. Land Use Policy, 28(4), 639-648. http://doi. org/10.1016/i.landusepol.2011.01.008

Zuluaga, G. P. (2000). Las nuevas funciones del espacio rural. Ensayos Frohum, 15, 1-12. 